\title{
Community-based training of medical students is associated with malaria prevention and treatment seeking behaviour for children under 5 years in Uganda: a study of MESAU-MEPI COBERS in Uganda
}

James Henry Obol ${ }^{1 *}$ (D), Peter Akera ${ }^{1}$, Pamela Atim Ochola', Wilfred Arubaku², Hussein Oria ${ }^{3}$, Kenneth Luryama Moi ${ }^{4}$, Denis Anywar Arony ${ }^{5}$ and Kaducu Felix ${ }^{1}$

\begin{abstract}
Background: Four university medical training institutions in Uganda have trained students at off-site health facilities under community-based education and Research Service (COBERS) programme for over 5 years. One of the major components of COBERS placement is for the students to provide health education in the communities about malaria as a major public health disease in Uganda. This study seeks to assess if targeted community-based medical education programme is associated with better prevention and treatment seeking behaviours in the management of malaria, a leading cause of morbidity and mortality of children under five in Uganda.
\end{abstract}

Methods: A cross-sectional survey was done to compare communities around health facilities where medical students were placed at COBERS sites with communities around similar health facilities where medical students were not placed (non-COBERS sites). We randomly selected two villages near each health facility and consecutively selected 10 households per village for interviews using nearest-neighbour method. We used a structured questionnaire to interview household heads on malaria prevention and treatment seeking behaviour for children under 5 years. We performed univariate analysis to determine site and demographic characteristics and performed a multivariate logistic regression to assess association between dependant and independent variables.

Results: Five hundred twenty-three (66.8\%) of the children under 5 years in COBERS communities slept under Insecticide Treated Nets (ITNs) the night before survey compared with 1451 (57.8\%) in non-COBERS communities ( $A O R=0.66, p=0.017) .100$ (60.0\%) of children under 5 years in COBERS communities sought care for fever within $24 \mathrm{~h}$ of onset compared with 268 (47.0\%) in non-COBERS communities ( $\mathrm{AOR}=0.71, P=0.009$ ).

Conclusion: The presence of COBERS in communities is associated with improved malaria prevention and treatment-seeking behaviour for parents of children under 5 years. Further study needs to be done to determine the long-term impact of COBERS training program on malaria control and prevention in Uganda, along with other effects of COBERS.

Keywords: COBERS, Malaria prevention and treatment seeking behaviour, Children under 5, Uganda

\footnotetext{
* Correspondence: obolh@yahoo.com

'Department of Public Health, Faculty of Medicine, Gulu University, P.O Box

166, Gulu, Uganda

Full list of author information is available at the end of the article
}

(c) The Author(s). 2018 Open Access This article is distributed under the terms of the Creative Commons Attribution 4.0 International License (http://creativecommons.org/licenses/by/4.0/), which permits unrestricted use, distribution, and reproduction in any medium, provided you give appropriate credit to the original author(s) and the source, provide a link to the Creative Commons license, and indicate if changes were made. The Creative Commons Public Domain Dedication waiver (http://creativecommons.org/publicdomain/zero/1.0/) applies to the data made available in this article, unless otherwise stated. 


\section{Background}

Malaria is a threat to the lives of about 3.2 billion people globally [1]. Children under five years are particularly vulnerable to severe disease and death when infected with malaria in endemic areas [2]. In Africa, malaria constitutes $10 \%$ of the disease burden and is the leading cause of under-5 mortality accounting for about 20\% [3]. Uganda has the third highest number of deaths attributable to malaria in Africa and has some of the highest recorded malaria transmission rates [4]. Malaria in Uganda constitutes a major public health problem responsible for between 30 and $50 \%$ of all outpatient consultations and an estimated 35\% of hospital admissions [5]. Malaria and malaria related-illnesses contributed to between 20 to $23 \%$ of deaths among children aged less than five years in Uganda [6]. The 2009 Uganda Malaria Indicator Survey showed that $52 \%$ of children under 5 years had malaria as determined by rapid diagnostic blood testing [7] while the 2014-15 Uganda Malaria Indicator Survey (UMIS) shows that overall, $31 \%$ of children had a fever in the two weeks preceding the survey [malaria indicator survey]. The 2014-15 UMIS also shows an improvement in testing for malaria at 36\% compared with $17 \%$ in 2009 [8].

Prompt access to effective malaria treatment is vital for the success of malaria control worldwide. The Roll Back Malaria (RBM) partnership set a target by the year 2010 of ensuring that $80 \%$ of those suffering from malaria have prompt access to, and can correctly use, affordable and appropriate treatment within $24 \mathrm{~h}$ of the onset of symptoms [9]. However, many African countries are far below these targets, with only a few of the fevers being treated promptly and effectively $[10,11]$. The 201415 UMIS also shows slight differences between rural and urban in the Percentages of under 5 children who took any Artemisinin-based Combination Therapy (ACT) same or next day at 40.2 for urban and 50.2 for rural [8].

The barriers to prompt and effective treatment for malaria among children under 5 in Uganda include: limited access to adequate treatment for malaria or fever, increasing resistance of malaria parasites to medicines, incorrect or inadequate malaria treatment at home or within communities [6] and fewer children with fever taking an antimalarial drug within the recommended time frame [4].

Insecticide-treated nets (ITNs) are effective in reducing malaria-related morbidity and mortality and because of this they are increasingly being utilized in sub-Saharan Africa and other malaria-endemic areas [12]. Despite this, only $43 \%$ of Ugandan children under the age of 5 years slept under an ITN the night before a national survey as noted in the Uganda Demographic and Health Survey (UDHS) report [4]. Barriers to malaria prevention among children under five in Uganda include low coverage of indoor residual spraying (IRS) and inadequate utilization of ITNs with only $46.5 \%$ of children reported to have slept under ITN or in a house sprayed with IRS thereby undermining efforts to control malaria among this vulnerable population [4]. However, in the 2014-15 UMIS shows an improvement in the use of ITN by children under 5 with the percentage who slept under an ITN the night before the survey was $74 \%$ compared with 33\% reported in the 2009 UMIS [8].

Given the severity of the malaria conditions in Uganda, there is need to explore innovative ways of improving utilization of effective interventions in prevention and treatment of malaria in communities. Training of health professionals at community level has been conceived as a sustainable initiative to address this gap. A consortium of undergraduate medical training universities in Uganda (Makerere University, Gulu University, Mbarara University of Science \& Technology and Kampala International University) formed the Medical Education for Equitable Services to All Ugandans (MESAU) in 2010, with funding from the NIH \& Fogarty International Centre under Medical Education Partnership Initiative (MEPI) and technical support from Johns Hopkins University and Case Western Reserve University.

All the Uganda MESAU institutions have trained their medical and other health professions students in community-based education research and service (COBERS) as a compulsory part of their health professions curricula for the last five years. Although each institution implements her program differently, the training involves having students participate in various primary care activities including health education and health promotion, immunisation, family planning counselling, growth monitoring and community outreach during their placements.

The COBERS is a modified version of Community-based education (CBE) which involves the integration of education and practice in the community within the learning process [13]. The increasing need to address the universal right to health and contributes to the "Health for All" strategy through promotion of primary health care (PHC) led to the integration of $\mathrm{CBE}$ into training curricula of many health professional training institutions in the world from the 1990s [14]. Results from studies done in Indonesia [15], Nigeria [16] and Uganda [17] indicate that community members appreciate $\mathrm{CBE}$ and believe that the students' activities were valuable.

The COBERS training is intended to have students develop competencies in dealing with common health conditions found at community level in Uganda, as well as contribute to improve health in these communities through research and services. During COBERS placement, the students get involved in Primary Health Care (PHC) activities like community mobilisation, home and 
school visits and health educational talks. Since malaria is the leading cause of morbidity and mortality in Uganda, all COBERS students provide health education on malaria prevention and treatment to patients at the health centres and during community outreaches.

MESAU is assessing the effectiveness and relevance of COBERS to learn lessons to improve the program, and to establish the credibility of COBERS to stakeholders, in part by identifying the broader impact of COBERS on communities. We report here part of the baseline study in which we compared malaria prevention and treatment-seeking behaviour for children under 5 years between communities near COBERS health facilities and non-COBERS communities.

\section{Methods}

\section{Design and setting}

This cross sectional analytical study assessed malaria prevention and treatment seeking behaviours for children under 5 years among communities who live near health facilities in Uganda. We compared communities near health facilities that have been used for student placements during COBERS (COBERS sites) with communities near health facilities that have not been used for COBERS (non-COBERS sites). COBERS placement range from 1st to 4th year of study and all the universities have a module on environmental health and disease control in their programs. This module prepares the students to engage with the community during health education and health promotion activity which they undertake during their COBERS placement. The COBERS placements last between 4 and 8 weeks at the health facilities with students who are in their 4th year of study spent more time providing curative and health promotion activity in the community. In Uganda, medical training institutions admit all qualified students from all over the country based on their choices and therefore there is regional representation in all the medical training institutions in Uganda. The COBERS sites were chosen by the medical training institutions base on geographical location of the medical training institutions which enable them to provide supervision of the medical students during their COBERS placement. The study population consisted of heads of households or adult members of the households who were knowledgeable about the health of all members living in the households within the study villages.

\section{Sampling}

Each institution had its own sampling frame consisting of at least twice the number of health facilities that the institution was likely to use over the next four years from 2011/12 academic year, but which had never been used for COBERS. The health facilities in the sampling frame were those within the geographical area that the institution was willing to send students to and should have met the minimum requirements established by MESAU, namely (i) administration and management willing to support the students; (ii) availability and willingness of qualified site tutors/preceptors; (iii) outpatients department in place; (iv) community outreach program in practice and (v) safe accommodation for students. In addition to the geographical area, each institution's health facilities were matched by level (HCIII, HCIV and District Hospital). The two facilities that were closest to each other in location and had the same level were paired, and one facility was randomly assigned to be used by students starting in the 2011/2012 academic year (intervention site) and the other to be used a comparison site. A health facility would not be an intervention site for one institution and a comparison site for another and neither would health facilities be intervention or comparison sites for more than one institution. These sites were selected purposively first by eliminating any Regional Referral Hospitals and any shared sites. The health facilities were then stratified into 10 regions as per UDHS report [4] and random selection within each region and matching to new sites within each region was done to ensure that all regions were represented. Table 1 shows how the health facilities were distributed. Because MESAU institutions had been implementing CBE for at least 5 years prior, a decision was made to add a cross-sectional aspect to the main evaluation, in which health facilities that had been used for CBE would be compared to the new sites selected for the main evaluation. Each institution then randomly selected from amongst the health facilities it uses for COBERS. For this study, these are referred to as COBERS sites, while the newly selected health facilities which will later be used in the post evaluation as

Table 1 Health facility characteristics

\begin{tabular}{|c|c|c|c|c|}
\hline \multirow[t]{2}{*}{ Characteristic } & \multicolumn{2}{|c|}{ COBERS $(N=30)$} & \multicolumn{2}{|c|}{ Non-COBERS $(N=90)$} \\
\hline & $\mathrm{n}$ & $\%$ & $\mathrm{n}$ & $\%$ \\
\hline \multicolumn{5}{|l|}{ Location } \\
\hline Rural & 27 & 90.0 & 73 & 81.1 \\
\hline Urban & 3 & 10.0 & 17 & 18.9 \\
\hline \multicolumn{5}{|l|}{ Level } \\
\hline Hospitals & 5 & 16.7 & 18 & 20.0 \\
\hline Health Centre IV & 13 & 43.3 & 31 & 34.4 \\
\hline Health Centre III & 12 & 40.0 & 41 & 45.6 \\
\hline \multicolumn{5}{|c|}{ Location with respect to malaria risk } \\
\hline High & 14 & 46.7 & 44 & 48.9 \\
\hline Medium & 5 & 16.7 & 16 & 17.8 \\
\hline Low & 11 & 36.7 & 30 & 33.3 \\
\hline
\end{tabular}


(intervention and comparison) are referred to as non-COBERS sites.

\section{Household survey}

A total of 240 villages (60 villages in COBERS and 180 villages in non-COBERS) within $2 \mathrm{~h}$ walking distance were randomly selected for the survey from around the 120 health facilities. In each health facility, names of all surrounding villages were written down and two villages were randomly selected for the survey. In each village, ten households were selected for interview after randomly selecting a starting point and using the nearest-next door method. All the households that had a child under five years were eligible for the survey. All households' heads or adult members of the households who were knowledgeable about the health of all members living in the households were interviewed about malaria prevention and treatment among children under 5 years using a structured questionnaire adopted from Demographic and Health Survey (DHS) (Additional file 1) between August 2012 and January 2013.

\section{Variables}

Our dependent variables were ITN use by under 5 years children in the previous night, experiencing fever among under 5 years children in last two weeks before the survey, treatment seeking for fever among under 5 years within one day of fever onset, and taking antimalarial drug within $24 \mathrm{~h}$ of fever onset. The independent variables were COBERS status (COBERS vs non-COBERS), household wealth quintile, sex of the child, household location (urban versus rural), and malaria risk zoning according to Uganda Bureau of Statistics [7].

\section{Data analysis}

Data was analysed using Stata 12 (StataCorp, College Station, Texas 77,845 USA). Univariate analysis was performed to determine site and demographic characteristics while the logistic regression was used to assess association between dependant and independent variables. We used principal component analysis method [18] to generate household wealth quintile base on household assets. This is because getting information on income and expenditure for household is not feasible among majority of Ugandans who lives in rural areas [18]. Data with multiple responses were recorded into binary variables [18]. The following socioeconomic indicator variables were used to classify the household economic status: Floor (Natural floor, Finished floor), Roof (Natural roofing, Finished roofing), Walls (Natural walls, Finished walls), Fuel for cooking (Electricity/LPG/Natural gas/Biogas/Kerosene/paraffin/Charcoal, Firewood/Straw/ shrubs/grass/Animal dung), Room for cooking (Yes, No), Have kitchen (Yes, No), Have chimney (Yes, No),
Electricity (Yes, No), Radio (Yes, No), Cassette player (Yes, No), Television (Yes, No), Mobile phone (Yes, No), Fixed telephone (Yes, No), Refrigerator (Yes, No), Table (Yes, No), Chair (Yes, No), Bed (Yes, No), Clock (Yes, No), Bicycle (Yes, No), Motorcycle/Scooter (Yes, No), Owning land for agriculture (Yes, No), Animal drawn-cart (Yes, No), Local cattle (Yes, No), Exotic cattle (Yes, No), Horse (Yes, No), Goats (Yes, No), Sheep (Yes, No), Chicken (Yes, No), Pigs (Yes, No), Rabbits (Yes, No), Truck (Yes, No), Ducks (Yes, No), Motor boat (Yes, No), Boat (Yes, No), Sofa set (Yes, No), cupboard (Yes, No) and Cook using (Open fire, open stove).

The above 37 socioeconomic indicator variables were loaded and run using Principal Component Analysis (PCA) to produce the components, eigenvalues, proportion and cumulative proportions plus eigenvectors. We then rotated factor 1 using orthogonal varimax (Kaiser off) method to produce component, variance, difference, proportion, cumulative proportions, rotated components and component rotation matrix for all the variables. To predict socioeconomic status, we scored the coefficients for orthogonal varimax rotation sum of squares (column loading) = 1 for all the variables and then generated socioeconomic status which is linear variable together with its frequency, percentage and cumulative percentage. To generate quintiles, we categorise the socioeconomic status using the cumulative percentage. The first quintile started from minimum up to $20 \%$ point on the cumulative percentage, the second quintile starts from $21 \%$ up to $40 \%$, the third quintile starts from $41 \%$ up to $60 \%$, fourth quintile starts from $61 \%$ up to $80 \%$ and the fifth quintile starts from $81 \%$ up to $100 \%$. The lowest $20 \%$ of households were classified as the poorest according to the economic status variable and the highest $20 \%$ as the least poor household [18]. We adjusted for data clustering at the health facility level.

\section{Results}

A total of 120 health facilities across Uganda were included in the study; 30 COBERS sites and 90 non-COBERS sites. As Table 1 shows, the COBERS and non-COBERS sites are not significantly different regarding rural-urban location, health facility level and location with respect to malaria risk zoning.

A total of 2399 households were interviewed with 600 households in the COBERS catchment areas and 1799 households in the non-COBERS areas. As Table 2 below shows, the households in the communities of the COBERS and non-COBERS sites are similar with respect to household location, size, sex and age distribution, including the proportion of children under five years of age in the respective populations and wealth quintiles.

A total of 1451 (58\%) of under 5 years children in non-COBERS sites used ITN while 523 (67\%) of children 
Table 2 Demographic characteristics of COBERS and Non-COBERS Households

\begin{tabular}{lllll}
\hline Characteristics & COBERS & \multicolumn{2}{l}{ Non-COBERS } \\
\hline Household location & $n$ & $\%$ & $n$ & $\%$ \\
$\quad$ Rural & 538 & 90.0 & 1469 & 82.0 \\
$\quad$ Urban & 62 & 10.0 & 330 & 18.0 \\
Household population & & & & \\
$\quad$ Rural & 3034 & 90.0 & 8289 & 84.3 \\
$\quad$ Urban & 336 & 10.0 & 1546 & 15.7 \\
Sex & & & & \\
$\quad$ Male & 1611 & 48.5 & 4685 & 48.4 \\
$\quad$ Female & 1709 & 51.5 & 4973 & 51.6 \\
Age groups (years) & & & & \\
0-20 & 1983 & 62.7 & 5804 & 62.8 \\
21-40 & 997 & 31.5 & 2855 & 30.9 \\
41-60 & 150 & 4.7 & 503 & 5.4 \\
$\quad$ 60 & 34 & 1.1 & 78 & 0.8 \\
Population of under 5 years & 783 & 20.5 & 2513 & 22.9 \\
Wealth quintile of households & & & & \\
Poorest Quintile & 111 & 21 & 305 & 20 \\
2nd Quintile & 99 & 18 & 319 & 21 \\
3rd Quintile & 115 & 21 & 302 & 19 \\
4th Quintile & 123 & 23 & 294 & 19 \\
Least Poor Quintile & 93 & 17 & 325 & 21 \\
\hline
\end{tabular}

under 5 years in COBERS communities used ITN (AOR $=0.66,95 \%$ CI $0.47-0.93 \&$ \&-Value $=0.017$ ). Table 3 summarises the results for factors associated with ITN use.

One hundred and sixty-seven (21\%) of the children under 5 years in the COBERS communities had fever in the last two weeks before survey compared to 566 (23\%) in the non-COBERS communities. Table 4 summarises the results for factors associated with having fever in the last two weeks before the survey.

One hundred (60\%) of under 5 children who had fever in the COBERS sites sought care within one day of fever onset compared to 268 (47\%) in non COBERS communities $(\mathrm{AOR}=0.71,95 \% \mathrm{CI} 0.55-0.91$ and $P$-value $=$ 0.009). Table 5 summarises results for factors associated with seeking care within one day of fever onset.

Also, 115 (69\%) of children with fever in the COBERS communities took antimalarial drug within $24 \mathrm{~h}$ of fever onset compared to 360 (64\%) in the non COBERS communities. Table 6 summarises the results for factors associated with taking antimalarial drug within $24 \mathrm{~h}$ of fever onset.

\section{Discussion}

This study shows significant differences between COBERS and non-COBERS sites. Children under 5 years at COBERS sites were more likely to use preventive and curative measures for malaria, although there was no difference in the prevalence of fever. This finding is consistent with that of a study done in Nigeria which showed that community-based medical training increased community awareness of preventive aspects for various communicable and non-communicable diseases

Table 3 Adjusted and Unadjusted O.R for Children under 5 years who slept under ITN the night before survey

\begin{tabular}{|c|c|c|c|c|c|c|c|c|c|}
\hline Background characteristics & Numerator & Denominator & $\%$ & OR & $95 \% \mathrm{Cl}$ & $p$-value & $\mathrm{AOR}$ & $95 \% \mathrm{Cl}$ & p-value \\
\hline \multicolumn{10}{|l|}{ Site status } \\
\hline COBERS & 523 & 783 & 66.8 & 1 & & & 1 & & \\
\hline Non-COBERS & 1451 & 2513 & 57.8 & 0.77 & $0.64-0.93$ & 0.06 & 0.66 & $0.47-0.93$ & 0.017 \\
\hline \multicolumn{10}{|l|}{ Sex } \\
\hline Female & 937 & 1579 & 59 & 1 & & & 1 & & \\
\hline Male & 998 & 1648 & 61 & 1.06 & $0.91-1.25$ & 0.453 & 1.05 & $0.89-1.24$ & 0.579 \\
\hline \multicolumn{10}{|l|}{ Sector } \\
\hline Rural & 1638 & 2819 & 58 & 1 & & & 1 & & \\
\hline Urban & 336 & 477 & 70 & 2.37 & $1.81-3.09$ & $<0.001$ & 1.9 & $1.23-2.94$ & 0.004 \\
\hline \multicolumn{10}{|l|}{ Wealth Quintile } \\
\hline Poorest Quintile & 270 & 496 & 54 & 1 & & & 1 & & \\
\hline 2nd Quintile & 352 & 669 & 53 & 1.16 & $1.02-1.31$ & 0.02 & 1.06 & $0.79-1.43$ & 0.691 \\
\hline 3rd Quintile & 523 & 895 & 58 & 1.44 & $1.28-1.63$ & $<0.001$ & 1.45 & $1.02-2.05$ & 0.039 \\
\hline 4th Quintile & 329 & 521 & 63 & 1.89 & $1.65-2.16$ & $<0.001$ & 1.65 & $1.12-2.43$ & 0.012 \\
\hline Least Poor Quintile & 328 & 420 & 78 & 3.98 & $3.38-4.69$ & $<0.001$ & 3.62 & $2.29-5.74$ & $<0.001$ \\
\hline
\end{tabular}


Table 4 Adjusted and Unadjusted O.R for under 5 children with fever in the last two weeks before survey

\begin{tabular}{|c|c|c|c|c|c|c|c|c|c|}
\hline Background characteristics & Numerator & Denominator & $\%$ & OR & $95 \% \mathrm{Cl}$ & $p$-value & $\mathrm{AOR}$ & $95 \% \mathrm{Cl}$ & p-value \\
\hline \multicolumn{10}{|l|}{ Site status } \\
\hline COBERS & 167 & 783 & 21 & 1 & & & 1 & & \\
\hline Non-COBERS & 566 & 2513 & 23 & 1.16 & $0.95-1.41$ & 0.149 & 1.05 & $0.68-1.62$ & 0.821 \\
\hline \multicolumn{10}{|l|}{ Sex } \\
\hline Female & 364 & 1579 & 23 & 1 & & & 1 & & \\
\hline Male & 357 & 1648 & 22 & 0.92 & $0.78-1.10$ & 0.361 & 0.91 & $0.77-1.07$ & 0.269 \\
\hline \multicolumn{10}{|l|}{ Sector } \\
\hline Rural & 612 & 2819 & 22 & 1 & & & 1 & & \\
\hline Urban & 121 & 477 & 25 & 1.28 & $1.01-1.61$ & 0.041 & 1.36 & $0.74-2.52$ & 0.32 \\
\hline \multicolumn{10}{|l|}{ Wealth Quintile } \\
\hline Poorest Quintile & 127 & 496 & 26 & 1 & & & 1 & & \\
\hline 2nd Quintile & 148 & 669 & 22 & 0.9 & $0.68-1.20$ & 0.482 & 0.86 & $0.60-1.22$ & 0.389 \\
\hline 3rd Quintile & 197 & 895 & 22 & 0.92 & $0.71-1.19$ & 0.523 & 0.89 & $0.65-1.21$ & 0.448 \\
\hline 4th Quintile & 110 & 521 & 21 & 0.89 & $0.66-1.20$ & 0.453 & 0.84 & $0.55-1.27$ & 0.398 \\
\hline Least Poor Quintile & 86 & 420 & 20 & 0.81 & $0.59-1.11$ & 0.197 & 0.7 & $0.43-1.15$ & 0.158 \\
\hline \multicolumn{10}{|l|}{ ITN use by under 5 children } \\
\hline No & 212 & 903 & 23 & 1 & & & 1 & & \\
\hline Yes & 505 & 1974 & 26 & 1.26 & $1.13-1.41$ & $<0.001$ & 1.19 & $0.92-1.54$ & 0.186 \\
\hline
\end{tabular}

OR Odds Ration, AOR Adjusted Odds Ratio

[16]. This study also shows differences in ITN use between urban and rural children with urban children more likely to sleep under ITN than rural children. In our study, $70 \%$ of children in urban compare with $58 \%$ in rural areas slept under ITN the night before the survey. However, this result is in contrast with the UMIS
2014-15 which shows that 71.5 of children under 5 years in urban areas slept under ITN compare with $75 \%$ of children under 5 years in rural areas [8]. Also, children in higher wealth quintile were more likely to use ITN than children from low wealth quintiles. Given that socio-economic status is a major determinant of the

Table 5 Adjusted and Unadjusted O.R for under 5 Children with fever in the two weeks before the survey for whom care was sought within one day

\begin{tabular}{|c|c|c|c|c|c|c|c|c|c|}
\hline Background characteristics & Numerator & Denominator & $\%$ & OR & $95 \% \mathrm{Cl}$ & $p$-value & $\mathrm{AOR}$ & $95 \% \mathrm{Cl}$ & $\mathrm{p}$-value \\
\hline \multicolumn{10}{|l|}{ Site status } \\
\hline COBERS & 100 & 167 & 60 & 1 & & & 1 & & \\
\hline Non-COBERS & 268 & 566 & 47 & 0.75 & $0.58-0.96$ & 0.023 & 0.71 & $0.55-0.91$ & 0.009 \\
\hline \multicolumn{10}{|l|}{ Sex } \\
\hline Female & 182 & 364 & 50 & 1 & & & 1 & & \\
\hline Male & 180 & 357 & 50 & 1.04 & $0.83-1.28$ & 0.745 & 1.03 & $0.83-1.29$ & 0.765 \\
\hline \multicolumn{10}{|l|}{ Sector } \\
\hline Rural & 298 & 612 & 49 & 1 & & & 1 & & \\
\hline Urban & 70 & 121 & 58 & 1.53 & $1.13-2.08$ & 0.007 & 1.71 & $1.21-2.41$ & 0.002 \\
\hline \multicolumn{10}{|l|}{ Wealth Quintile } \\
\hline Poorest Quintile & 59 & 127 & 46 & 1 & & & 1 & & \\
\hline 2nd Quintile & 72 & 148 & 49 & 0.78 & $0.55-1.10$ & 0.157 & 0.73 & $0.52-1.04$ & 0.084 \\
\hline 3rd Quintile & 93 & 197 & 47 & 0.96 & $0.70-1.34$ & 0.83 & 0.91 & $0.65-1.27$ & 0.591 \\
\hline 4th Quintile & 65 & 110 & 59 & 1.38 & $0.95-2.00$ & 0.089 & 1.28 & $0.88-1.87$ & 0.192 \\
\hline Least Poor Quintile & 44 & 86 & 51 & 0.82 & $0.54-1.22$ & 0.333 & 0.68 & $0.45-1.05$ & 0.082 \\
\hline
\end{tabular}


Table 6 Adjusted and Unadjusted O.R for under 5 years Children with fever in the two weeks before the survey who were given antimalarial drugs within one day

\begin{tabular}{|c|c|c|c|c|c|c|c|c|c|}
\hline Background characteristics & Numerator & Denominator & $\%$ & OR & $95 \% \mathrm{Cl}$ & $p$-value & $\mathrm{AOR}$ & $95 \% \mathrm{Cl}$ & p-value \\
\hline \multicolumn{10}{|l|}{ Site status } \\
\hline COBERS & 115 & 167 & 69 & 1 & & & 1 & & \\
\hline Non-COBERS & 360 & 566 & 64 & 0.77 & $0.53-1.10$ & 0.15 & 0.6 & $0.27-1.32$ & 0.204 \\
\hline \multicolumn{10}{|l|}{ Sex } \\
\hline Female & 236 & 364 & 65 & 1 & & & 1 & & \\
\hline Male & 229 & 357 & 64 & 0.93 & $0.69-1.26$ & 0.658 & 0.85 & $0.48-1.48$ & 0.558 \\
\hline \multicolumn{10}{|l|}{ Sector } \\
\hline Rural & 392 & 612 & 64 & 1 & & & 1 & & \\
\hline Urban & 83 & 121 & 69 & 1.28 & $0.82-2.00$ & 0.275 & 1.38 & $0.64-2.99$ & 0.409 \\
\hline \multicolumn{10}{|l|}{ Wealth Quintile } \\
\hline Poorest Quintile & 80 & 127 & 63 & 1 & & & 1 & & \\
\hline 2nd Quintile & 93 & 148 & 63 & 0.93 & $0.58-1.50$ & 0.781 & 0.62 & $0.25-1.54$ & 0.297 \\
\hline 3rd Quintile & 121 & 197 & 61 & 1.24 & $0.78-1.97$ & 0.365 & 1.44 & $0.56-3.70$ & 0.449 \\
\hline 4th Quintile & 72 & 110 & 65 & 0.98 & $0.60-1.61$ & 0.936 & 0.92 & $0.35-2.42$ & 0.858 \\
\hline Least Poor Quintile & 66 & 86 & 77 & 1.27 & $0.71-2.28$ & 0.428 & 1.87 & $0.61-5.79$ & 0.274 \\
\hline
\end{tabular}

OR Odds Ration, AOR Adjusted Odds Ratio

ownership and use of ITN among children under 5 years $[4,19]$, it is important to note that there is no difference in socio-economic status between the households in the COBERS and non- COBERS communities. Thus, socio-economic status does not account for the observed difference in the use of ITNs by under-5-year children between the COBERS and non-COBERS sites. The difference could be attributed to interaction with medical students.

There was no statistical difference between COBERS and non-COBERS sites regarding children under 5 years experiencing fever. However, there was statistical significant difference between COBERS communities and non-COBERS communities regarding children under 5 years who sought care within the recommended time frame of $24 \mathrm{~h}(\mathrm{AOR}=0.71, p=0.009)$.

Students who are placed for COBERS get involved in PHC activities like community mobilisation, home and school visits and health educational talks. Research findings from other studies suggest that community members reported that they have seen improvements in health and health seeking behaviours and increased community participation in PHC because of CBE [16]. PHC is intended to address the major local health problems of a country population and it is the interface between the community and the health system [20].

Also, important to note is that a greater number of children received a drug (antimalarial or otherwise) within the recommended time frame of $24 \mathrm{~h}$ both in the COBERS and non COBERS communities compared to those who sought care in both COBERS and
non-COBERS communities. Taken together, these findings suggest that there is possible self-medication or medication in the home. Plausibly, this could be attributed to inherence drug stock out at the health facilities in Uganda as has been noted in the annual health sector performance report [6]. However, there was a statistically significant difference between the COBERS and non-COBERS sites in seeking care within one day for children under 5 years of age. Thus, although there is possibly medication taking place in the home in both COBERS and non-COBERS communities, the COBERS communities are more likely to seek care for children under five with fever than the non-COBERS communities. Other studies have shown that several African countries were far from achieving the RBM set targets of $80 \%[10,11,21]$. RBM aimed at ensuring that those suffering from malaria have prompt access to and able to correctly use affordable and appropriate treatment within $24 \mathrm{~h}$ of symptom onset [9].

\section{Study limitation}

There are some limitations to consider while interpreting our findings. We did not test those who reported to be having fever for presence of malaria parasites but rather took all persons who reported to have had febrile illness as malaria. This was subjective because they were based on head of household or mother perception of illness and were not necessarily validated by medical personnel thus it may not be true that all febrile illness is malaria. Therefore, we could have overestimated the incidence of malaria in 
the study population. Secondly, we can not discount social desirability bias in our study since most parents or household heads may want to show that they are complying with government program. Thirdly, the cross-sectional design makes it difficult to determine whether the observed outcomes are because of exposure to COBERS. However, despite this, our study has shown that COBERS training is associated with improve malaria prevention through sleeping under ITNs and seeking treatment for fever within the recommended time frame of $24 \mathrm{~h}$ for children under 5 years in Uganda. Besides, our study is the first of its kind to be conducted in Uganda to assess COBERS contribution to community health.

\section{Conclusion}

This study provides some evidence to suggest that COBERS training has influenced health behaviours in the communities where students are placed for preventive care for children with malaria. Further studies are needed to assess the causal relationship, and the longer-term impact of COBERS on community health and other objectives of the COBERS program in Uganda.

\section{Additional file}

Additional file 1: Household Questionnaire used for the baseline collection of data during survey. (PDF 136 kb)

\section{Abbreviations \\ AOR:: Adjusted Odds Ratio; CBE:: Community-Based Education; COBERS:: Community-Based Education Research and Service; COR:: Crude Odds Ration; IRS:: Indoor Residual Spraying; ITNs:: Insecticide-Treated Nets; MEPI:: Medical Education Partnership Initiative; MESAU:: Medical Education for Equitable Services to All Ugandans; RBM:: Roll Back Malaria; UDHS:: Uganda Demographic and Health Survey; UMIS.: Uganda Malaria Indicator Survey}

\begin{abstract}
Acknowledgements
The authors would like to thank the MESAU - MEPI consortium for making this study possible through technical and financial support and the Johns Hopkins University team (Prof. David Peters \& Prof. Bob Bollinger) for the technical support provided during the inception up to the conclusion of the study. We are grateful to our Research Assistants who helped us in data collection. We are indebted to our research participants who provided us with valuable information. The content is solely the responsibility of the authors and does not necessarily represent the official views of the Fogarty International Center or the National Institutes of Health.
\end{abstract}

\section{Funding}

The project described was supported by the MESAU-MEPI Programmatic Award through Award Number 1R24TW008886 from the Fogarty International Centre.

\section{Availability of data and materials}

The data that support the findings of this study are available from MESAU Consortium Secretariat, but restrictions apply to the availability of these data, which were used under license for the current study, and so are not publicly available. Data are however available from the authors upon reasonable request and with permission of MESAU Consortium Secretariat.

\section{Authors' contributions}

$\mathrm{JHO}$ : Designed the study, wrote the proposal, reviewed literature, devised data collection tool, carried out field data collection, performed statistical analysis of the data, interpreted the results and drafting of manuscript. PA: Reviewed literature, drafted proposal, edited data collection tool, carried out field data collection and drafting of manuscript. PAO: Reviewed literature and participated in drafting of manuscript. WA: Designed the study, wrote the proposal, reviewed literature, devised data collection tool, carried out field data collection, reviewed the manuscript. HO: Edited data collection tool, interpreted results and drafted the manuscript. KLM: Reviewed literature, interpreted results and drafted the manuscript. DAA: Reviewed literature and drafted the manuscript. FK: Reviewed literature, interpreted the results and drafted the manuscript. All authors read and approved the manuscript in its current form.

Ethics approval and consent to participate

Ethical approval of the study was obtained from MakCHS School of Medicine Research and Ethics Committee (SOMREC). The study was registered with Uganda National Council for Science and Technology. Each research participant provided a written informed consent to participate in the study after the study procedures, benefits and risks were explained to him/her.

\section{Competing interests}

The authors declare that they have no competing interests.

\section{Publisher's Note}

Springer Nature remains neutral with regard to jurisdictional claims in published maps and institutional affiliations.

\section{Author details}

${ }^{1}$ Department of Public Health, Faculty of Medicine, Gulu University, P.O Box 166, Gulu, Uganda. ²Deaprtment of Dental Surgery, Faculty of Medicine Mbarara University of Science and Technology, P.O Box 1410, Mbarara, Uganda. ${ }^{3}$ Department of Pharmacy, School of health Sciences Makerere University, P.O Box 7072, Kampala, Uganda. ${ }^{4}$ Department of Medical Microbiology \& Immunology, Faculty of Medicine, Gulu University, P.O Box 166, Gulu, Uganda. ${ }^{5}$ Department of Biochemistry, Faculty of Medicine, Gulu University, P.O Box 166, Gulu, Uganda.

Received: 6 July 2016 Accepted: 1 June 2018

Published online: 08 June 2018

\section{References}

1. Aluko JO, Oluwatosin $\mathrm{AO}$. Utilization of insecticide treated nets during pregnancy among postpartum women in Ibadan, Nigeria: a cross-sectional study. BMC Pregnancy and Childbirth. 2012;12:21.

2. Megan L, Gatakaa H, Evance I, Poyer S, et al. Monitoring fever treatment behaviour and equitable access to effective medicines in the context of initiatives to improve ACT access: baseline results and implications for programming in six African countries. Malar J. 2011:10:327.

3. Fatungase $\mathrm{KO}$, Amoran $\mathrm{OE}$, Alausa $\mathrm{KO}$. The effect of health education intervention on the home management of malaria among the caregivers of children aged under 5 years in Ogun state, Nigeria. Eur J Med Res. 2012;17:11.

4. Uganda Bureau of Statistics (UBOS) and ICF International (2012). Uganda Demographic and Health Survey 2011 Report. Available at: https:// dhsprogram.com/pubs/pdf/fr264/fr264.pdf. Accessed 13 July 2015.

5. Henry OJ, Lagoro KD, Orach CG. Prevalence of malaria and treatment seeking Behaviours among pregnant women in post conflict internally displaced persons' camps in Gulu District. International Scholarly Research Network Public Health. 2011; https://doi.org/10.5402/2012/164935.

6. Ministry of Health Uganda. Annual Health Sector Performance Report for financial year 2009/10. Available at: http://library.health.go.ug/publications/ health-workforce-human-resource-management/performance-management/ annual-health-secto-8. Accessed on $13^{\text {th }}$ July 2015.

7. Uganda Bureau of Statistics (UBOS) and ICF Macro, 2010. Uganda malaria Indicator survey 2009. Available at: https://www.dhsprogram.com/pubs/pdf/ MIS6/MIS6.pdf. Accessed on $17^{\text {th }}$ July 2015.

8. Uganda Malaria Indicator Survey report 2014-15. Available at: http://library. health.go.ug/publications/service-delivery-diseases-control-preventioncommunicable-diseases/malaria/uganda-2. Accessed on $17^{\text {th }}$ July 2015. 
9. Jane C, Vincent O, Catherine M. Barriers to prompt and effective malaria treatment among the poorest population in Kenya. Malar J. 2010;9:144. https://doi.org/10.1186/1475-2875-9-144.

10. Hetzel MW, Obrist B, Lengeler C, Msechu JJ, Nathan R, Dillip A, Makemba AM, Mshana C, Schulze A, Mshinda H. Obstacles to prompt and effective malaria treatment lead to low community-coverage in two rural districts of Tanzania. BMC Public Health. 2008;8:317.

11. Zurovac D, Tibenderana JK, Nankabirwa J, Ssekitooleko J, Njogu JN, Rwakimari JB, Meek S, Talisuna A, Snow RW. Malaria case-management under artemether-lumefantrine treatment policy in Uganda. Malar J. 2008;7:181.

12. Benjamin KG, Ghattas H, Essé C, Nsanzabana C, Rohner F, Utzinger J, Faragher BE, Tschannen AB. The use of insecticide-treated nets for reducing malaria morbidity among children aged 6-59 months, in an area of high malaria transmission in central Côte d'Ivoire. Parasit Vectors. 2010;3:91.

13. World Health Organisation. Community-based education of health personnel. Geneva: World Health Organisation; 1987. Available at: http:// apps.who.int/iris/bitstream/handle/10665/41714/WHO_TRS_746. pdf? sequence $=1$ \&isAllowed $=y$. Accessed on $17^{\text {th }}$ July 2015 .

14. Bor D. Position paper on community-based education for health professionals. Educ Health (Abingdon). 2003;16(3):400-4.

15. Kristina TN, Majoor GD, van der Vleuten CP. Comparison of outcomes of a community-based education programme executed with and without active community involvement. Med Educ. 2006;40(8):798-806.

16. Omotara BA, Padonu MO, Yahya SJ. Assessment of the impact of community-based medical education of the University of Maiduguri on communities in three local government areas of Borno state, Nigeria: community leaders' perspectives. Educ Health (Abingdon). 2004;17(1):6-16.

17. Mbalinda SN, Plover CM, Burnham G, Kaye D, Mwanika A, Oria H, Okullo I, Muhwezi W, Groves S. Assessing community perspectives of the community based education and service model at Makerere University, Uganda: a qualitative evaluation. BMC Int Health Hum Rights. 2011;11(Suppl 1):S6.

18. Vyas S, Kumaranayaker L. Constructing socio-economic status indices: how to use principal components analysis. Health Policy Plan. 2006;21(6):459-68. https://doi.org/10.1093/heapol/czl029

19. Haileselassie B, Ali A. Assessment of Insecticide Treated Nets Coverage for Malaria Control in Kafta-Humera District, Tigray: Possession versus use by high-risk groups. EthiopJHealth Dev. 2008;22(3):259-67.

20. Declaration of Alma-Ata. In: International conference on primary health care: 1978; Alma-Ata, USSR; 1978. Available at: http://www.who.int/publications/ almaata_declaration_en.pdf. Accessed on $17^{\text {th }}$ July 2015.

21. Ahorlu CK, Koram KA, Ahorlu C, de Savigny D, Weiss MG. Socio-cultural determinants of treatment delay for childhood malaria in southern Ghana. Tropical Med Int Health. 2006;11(7):1022-31.

\section{Ready to submit your research? Choose BMC and benefit from:}

- fast, convenient online submission

- thorough peer review by experienced researchers in your field

- rapid publication on acceptance

- support for research data, including large and complex data types

- gold Open Access which fosters wider collaboration and increased citations - maximum visibility for your research: over $100 \mathrm{M}$ website views per year

At BMC, research is always in progress.

Learn more biomedcentral.com/submissions 